\title{
An analysis of offshore wind farm SCADA measurements to identify key parameters influencing the magnitude of wake effects
}

\author{
Niko Mittelmeier ${ }^{1}$, Julian Allin ${ }^{1}$, Tomas Blodau ${ }^{1}$, Davide Trabucchi ${ }^{2}$, Gerald Steinfeld ${ }^{2}$, Andreas Rott ${ }^{2}$, \\ and Martin Kühn ${ }^{2}$ \\ ${ }^{1}$ Senvion GmbH, Überseering 10, 22297 Hamburg, Germany \\ ${ }^{2}$ ForWind - University of Oldenburg, Institute of Physics, Küpkersweg 70, 26129 Oldenburg, Germany
}

Correspondence to: Niko Mittelmeier (niko.mittelmeier@senvion.com)

Received: 31 December 2016 - Discussion started: 3 February 2017

Revised: 21 May 2017 - Accepted: 8 September 2017 - Published: 18 October 2017

\begin{abstract}
For offshore wind farms, wake effects are among the largest sources of losses in energy production. At the same time, wake modelling is still associated with very high uncertainties. Therefore current research focusses on improving wake model predictions. It is known that atmospheric conditions, especially atmospheric stability, crucially influence the magnitude of those wake effects. The classification of atmospheric stability is usually based on measurements from met masts, buoys or lidar (light detection and ranging). In offshore conditions these measurements are expensive and scarce. However, every wind farm permanently produces SCADA (supervisory control and data acquisition) measurements. The objective of this study is to establish a classification for the magnitude of wake effects based on SCADA data. This delivers a basis to fit engineering wake models better to the ambient conditions in an offshore wind farm. The method is established with data from two offshore wind farms which each have a met mast nearby. A correlation is established between the stability classification from the met mast and signals within the SCADA data from the wind farm. The significance of these new signals on power production is demonstrated with data from two wind farms with met mast and long-range lidar measurements. Additionally, the method is validated with data from another wind farm without a met mast. The proposed signal consists of a good correlation between the standard deviation of active power divided by the average power of wind turbines in free flow with the ambient turbulence intensity (TI) when the wind turbines were operating in partial load. It allows us to distinguish between conditions with different magnitudes of wake effects. The proposed signal is very sensitive to increased turbulence induced by neighbouring turbines and wind farms, even at a distance of more than 38 rotor diameters.
\end{abstract}

\section{Introduction}

Wake effects are one of the largest sources of losses in offshore energy yield assessment. This makes wake modelling very important, and much research is ongoing to improve wake model predictions. In the latest offshore CREYAP benchmark exercise (Comparative Resource and Energy Yield Assessment Procedure), wake modelling was found to be the prediction with the highest variation among the participants (Mortensen et al., 2015).
In order to use a wake model for validating the performance of an operating offshore wind farm (Mittelmeier et al., 2017), prediction uncertainties need to be reduced. Hansen et al. (2012) studied wake effects at the offshore wind farm Horns Rev in different atmospheric conditions and revealed an influence on the wake magnitude. They also compared turbulence intensities for different stability classes as a function of the wind speed. Below $7 \mathrm{~m} \mathrm{~s}^{-1}$ a clear increase in turbulence intensities can be noticed. Above $7 \mathrm{~m} \mathrm{~s}^{-1}$ neutral to unstable conditions are distinguishable from more stable conditions with a constant threshold up to nominal wind speed. 
Dörenkämper et al. (2014) draw a link from stability via shear to turbulence intensity motivated by the studies of Tambke et al. (2005) and show its impact on wake effects. Sanz Rodrigo et al. (2015) compared different stability classification methodologies with data from FINO 1 and presented the behaviour of shear and turbulence intensity for the proposed atmospheric stability classes. The authors concluded that in this particular case TI correlates well for stable cases, but at nearly neutral and unstable cases, shear should enable better distinction between their proposed nine classes. Atmospheric stability and turbulence intensity have been identified as main drivers for the variation in power production under waked conditions (Dörenkämper et al., 2012; Westerhellweg et al., 2014; Iungo and Porté-Agel, 2014). Therefore state-of-theart engineering wake models for industrial application, like Fuga or FarmFlow, are able to take stability effects into account (Özdemir et al., 2013; Ott and Nielsen, 2014).

Stability classification is based on measurements from met masts, buoys or whether it is assisted by remote sensing devices, such as light detection and ranging (lidar) or sound detection and ranging (sodar). For offshore use, these devices are very expensive and therefore often not permanently available. In several studies, lidars have been used to assess the wind speed recovery behind the turbine, and wake models have been tuned to match the measured wind speed (Beck et al., 2014; More and Gallacher, 2014).

The purpose of this paper is to investigate wind farm operational data and establish methods of identifying correlations between SCADA statistics and wind turbine wake behaviour caused by different atmospheric conditions.

\section{Wind farms and measurements}

For this investigation, we select three offshore wind farms, alpha ventus, Nordsee Ost and Ormonde. The first two wind farms have a well-equipped met mast and provide highquality measurements of hub-height wind speed, wind direction, shear intensity, turbulence intensity and water temperature.

\subsection{Alpha ventus}

The wind farm alpha ventus (AV) is located about $45 \mathrm{~km}$ north of the island of Borkum in the North Sea. It consists of 12 turbines of the $5 \mathrm{MW}$ class with a rotor diameter of $126 \mathrm{~m}$ and was commissioned in April 2010. The six northern turbines (AV1-AV6) were manufactured by Senvion. The six turbines in the southern part of the wind farm were manufactured by Adwen and are not considered in this analysis. The FINO1 research met mast is located only 3.2 D (rotor diameters) west of turbine AV4.

The layout of the northern part of alpha ventus (See Fig. 1) allows for an investigation of the wake behaviour in singleand double-wake conditions for westerly wind directions. Data were used from March 2011 to January 2015. After Jan-

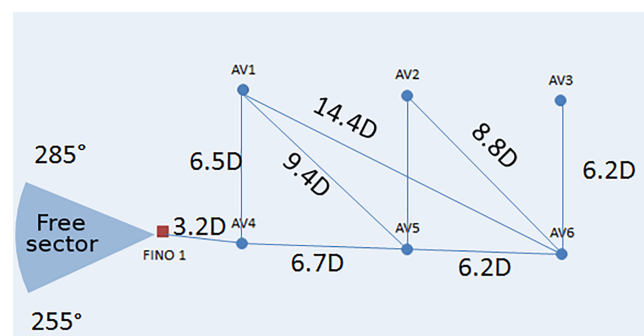

Figure 1. Schematic layout of the northern part of alpha ventus wind farm (circles) and FINO1 met mast (red square) with free-flow sector and distance in rotor diameters.

uary 2015 no data were used because the installation of the Trianel wind farm in the west is suspected to have changed the environmental conditions of alpha ventus by adding extra turbulence to the inflow.

\subsection{Nordsee Ost}

The wind farm Nordsee Ost (NO) is located about $35 \mathrm{~km}$ north-west of the island of Heligoland in the North Sea. The 48 Senvion turbines have a rated power of $6 \mathrm{MW}$ each and a rotor diameter of $126 \mathrm{~m}$. The met mast is located in the southwestern corner of the wind farm (See Fig. 2). In the south, the neighbouring wind farm Meerwind Ost/Süd reduces the sector of free flow for the met mast and the possibilities to study multiple wakes higher than triple-wake conditions without disturbing effects from Meerwind.

The wind farm Nordsee Ost was fully commissioned in 2015. Data for this analysis are selected from November 2015 to November 2016. A correlation analysis (described in Sect. 3.2) is performed and the data from a long-range lidar are analysed. This lidar measurement campaign took place within the European research project "ClusterDesign".

\subsection{Ormonde}

The Ormonde wind farm consists of 30 Senvion turbines with a rated power of $5 \mathrm{MW}$ each and a rotor diameter of $126 \mathrm{~m}$. The wind farm is located in the Irish Sea $10 \mathrm{~km}$ west of the Isle of Walney. The selected data are from January 2012 to January 2014. During this period, neighbouring wind farms were operational. Located in the south-west are Walney 1 (51×SWT-3.6-107 Siemens) and Walney $2(51 \times$ SWT-3.6120 Siemens). Located in the south there is West of Duddon Sands (SWT-3.6-120 Siemens; fully commissioned 30 October 2014), and in the south-east there is Barrow (V903.0 MW Vestas).

The farm layout displayed in Fig. 3 is structured in a regular array which allows for a comparison of several multiplewake situations. The inner farm turbine distance for the investigated wake situation from the south-west is $6.3 \mathrm{D}$ and from the north-west it is $4.3 \mathrm{D}$. 


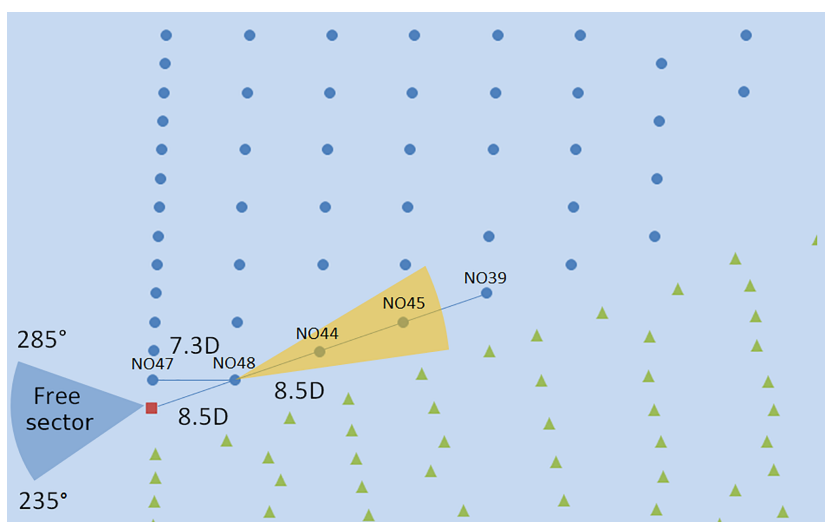

Figure 2. Nordsee Ost wind farm (blue circles) with neighbouring wind farm Meerwind Süd (green triangles), met mast (red square) and distance in rotor diameters (D). The orange area indicates the plan position indicator (PPI) scan from the Windcube 200S mounted on the helicopter platform of NO48 (described in Sect. 2.5).

\subsection{SCADA and meteorological data}

The SCADA data from all wind farms and the meteorological data consist of $10 \mathrm{~min}$ statistics. Each turbine provides wind speed, wind direction, active power, yaw position and pitch angle. The operational condition of the wind turbine, which is used for the correlation with the met mast turbulence intensity, is categorised by the minimum active power $>10 \mathrm{~kW}$, the maximum pitch angle $<3^{\circ}$ and the standard deviation of the yaw position $<5^{\circ}$. These filter criteria ensure that no standstills, curtailments or too-large yaw activities are included in the data. Furthermore, any succeeding 10 min measurement period after a turbine restart is deleted to give the flow enough time to develop. SCADA data are also deleted if the waked turbine produces more power than the free-flow turbine. Implausible met mast data are removed and wind directions are corrected for bias by using the orientation of the maximum wake deficit. For the correlation, only sectors of free-flow conditions are used. Averages of $30 \mathrm{~min}$ water temperature are recorded by buoys at FINO1 and linearly interpolated into the SCADA data.

\subsection{Long-range lidar measurements}

Within the ClusterDesign research project funded by the European Union, a long-range lidar measurement campaign was realised. A Windcube 200S (WLS200S) lidar with scan head was placed on the helicopter platform of NO48 (See Fig. 2) from November 2015 to May 2016. A differential GPS system composed of three antenna GNSS systems of the type Trimble SPS855/SPS555H allows for additional measurements of turbine yaw, nacelle pitch and roll angle. One lidar measurement cycle takes about $200 \mathrm{~s}$. It includes five plan position indicator (PPI) scans followed by one range height indicator (RHI) scan. Both scans cover a sector of $30^{\circ}$ on the horizontal and vertical plane respectively and are centred on the rotor axis. The scan trajectories have an angular resolution of $1^{\circ}$ and measure the wind speed component along the measuring direction every $25 \mathrm{~m}$ from 100 to $2500 \mathrm{~m}$. The lidar data are filtered to exclude measurements with a poor signal intensity affected by hard targets and considered outliers.

The horizontal 10 min average wind speed is calculated on a well-defined grid under the assumption of a negligible vertical component of the wind. The average of the wind component measured by the lidar during the considered time interval is included in the region of interest of the addressed grid point. The average $10 \mathrm{~min}$ wind direction is provided by the met mast. When the latter measurement is not available, the turbine yaw provided by the differential GPS system is used to estimate the wind direction. A detailed description of the lidar data preprocessing can be found in Schneemann et al. (2016).

For the assessment in this paper we are using averages of $10 \mathrm{~min}$ periods of horizontal wind speed data evaluated from PPI scans of the wake behind NO48 (See Fig. 2). A multiplewake situation can be observed at a wind direction of $237.5^{\circ}$ when NO45 is in the wake of NO44 and NO48. In Fig. 4 (top) an example for a PPI scan at hub height with averages of $10 \mathrm{~min}$ periods of the horizontal wind speed data is displayed. Hard targets, like blades and nacelles, prevent reasonable wind speed measurement. Wind speeds at these blind regions and between the beam directions are linearly interpolated. The distance from turbine NO48 is normalised by its rotor diameter and the wind speeds are normalised with the corresponding wind speed measured at the met mast. The different colours represent the wind speed relative to the wind speed at the given met mast location. The black crosses display the locations of the estimated wind speed minima for each measured distance equal to or greater than $2 \mathrm{D}$. These minima should represent the centre of the wake. They are derived at each downstream cross section with a Gaussian smoothing (Hamilton, 2015) applied to the lidar data before fitting a double-Gaussian-type velocity deficit in the near wake $(\leq 2.5 \mathrm{D})$ and a single-Gaussian-type in the far wake. This distinction prevents an overestimation of the deficit in the near wake where the nacelle still has an influence on the flow shape (Keane et al., 2016). The Gaussian minima (black crosses) do not follow a straight line for the entire scan. This should not be interpreted as meandering as we are looking at averages of $10 \mathrm{~min}$ periods.

The lower graph of Fig. 4 shows the resulting normalised wind speeds over the normalised distance from NO48. The black line with the corresponding black crosses refers to the fitted values of the Gaussian fits. 


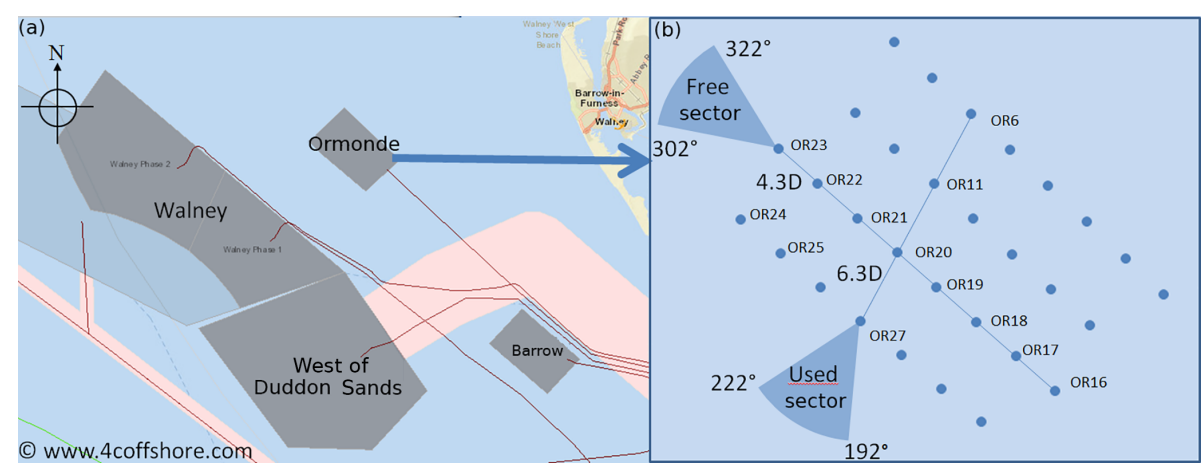

Figure 3. (a) Ormonde and neighbouring wind farms. (b) Ormonde wind farm layout with distances in rotor diameters (D) and sectors selected for the analysis.
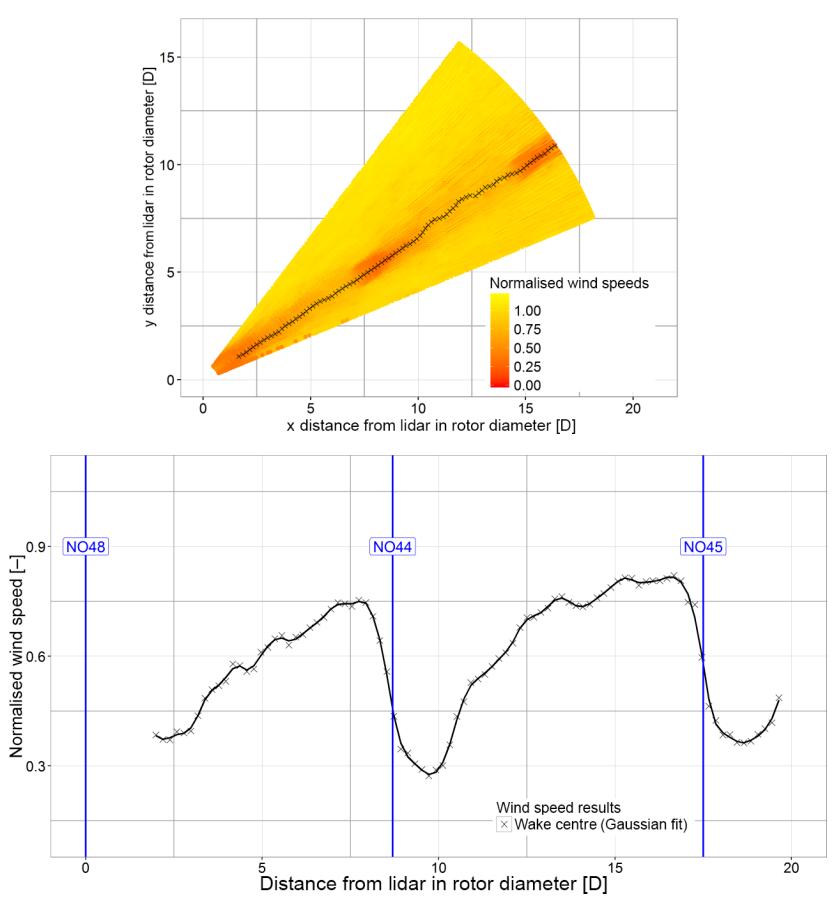

Figure 4. Upper plot: visualisation of the horizontal plan position indicator (PPI) scans downstream of NO48. Wind speed is normalised with the inflow wind speed measured at the met mast. The black crosses are the locations of the wind speed minima derived from a Gaussian fitting for each measurement distance. Bottom plot: normalised wind speed as a function of the distance in rotor diameters extracted from the top plot for the Gaussian-fitted minima (black crosses).

\section{Method}

Following the objective of proposing a signal based on SCADA data that enables us to identify the magnitude of wake effects, we first establish stability classification based on Monin-Obukhov surface-layer theory (Monin and Obukhov, 1954) and met mast turbulence intensity. Both approaches can be found in many publications and their influ- ence on the magnitude of wake effects is reported. Secondly, SCADA signals which are affected by turbulence intensity are proposed and the ability of these signals to classify low, medium and high wake effects is analysed.

\subsection{Stability and turbulence intensity classification}

For the determination of atmospheric stability we follow the approach suggested by Ott and Nielsen (2014). Their iterative method is implemented in the software AMOK and derives the inverse Monin-Obukhov length $1 / L$ from air temperature and wind speed measured at $z[\mathrm{~m}]$ and water surface temperature. Many different thresholds for stability classification have been published and breakdowns from three to nine different classes can be found in the literature (Archer et al., 2016; Sanz Rodrigo et al., 2015). Dörenkämper (2015) and Rajewski et al. (2013) have suggested a classification into unstable, neutral and stable classes (Table 1) based on turbulence intensity (TI) and the dimensionless MoninObukhov length $\zeta=\frac{z}{L}$.

Both classifications and their impact on wake effects are compared with FINO1 data in Sect. 4.1 and alpha ventus data in Sect. 4.2.

\subsection{Correlation analysis}

At wind farms with no met mast we have to rely on other signals to describe the differences in power production under different atmospheric conditions. To find the best substitute for a met-mast-measured turbulence intensity, several SCADA signals that are affected by turbulence are correlated to the met mast turbulence intensity, which is defined as

$\mathrm{TI}_{\text {mast }}=\frac{\sigma_{u_{\text {mast }}}}{\overline{u_{\text {mast }}}}$.

Analogous to Eq. (1), we define

$\mathrm{TI}_{\mathrm{WT}}=\frac{\sigma_{u_{\mathrm{WT}}}}{\overline{u_{\mathrm{WT}}}}$

as the turbulence intensity measured with the wind speed anemometer on top of the nacelle with $\bar{u}$ being the average 
Table 1. Definition of stratification with turbulence intensity and the dimensionless Monin-Obukhov length $\zeta$.

\begin{tabular}{lll}
\hline Classification & Dörenkämper (2015) & Rajewski et al. (2013) \\
\hline Unstable & $\mathrm{TI}>6 \%$ & $\zeta<-0.05$ \\
Neutral & $4 \%<\mathrm{TI}<6 \%$ & $-0.05 \leq \zeta \leq 0.05$ \\
Stable & $\mathrm{TI}<4 \%$ & $\zeta>0.05$
\end{tabular}

of 10 min periods of horizontal wind speed and its standard deviation $\sigma_{u}$. Göçmen and Giebel (2016) evaluated $1 \mathrm{~Hz}$ data from Lillgrund and Horns Rev I and found good turbulence estimators by using a turbine-derived "wind estimate" from lookup tables. When only $10 \mathrm{~min}$ statistics are available, the signals of interest are the standard deviation of the turbine power,

$\mathrm{PO}_{\text {std }}=\sigma_{\mathrm{P}}$,

and the normalisation of this signal with the average power $\bar{P}$. This leads to

$\mathrm{PO}_{\mathrm{TI}}=\frac{\sigma_{\mathrm{P}}}{\bar{P}}$.

Turbulence intensity is dependent on wind speed (Türk and Emeis, 2010). Wake effects are most pronounced at partial load, and in this range, shear and $\mathrm{PO}_{\mathrm{TI}}$ are even more related to wind speed. The relationship between $\mathrm{PO}_{\mathrm{TI}}$ and the wind speed can be approximated with a third-order polynomial,

$y=\beta_{0}+\beta_{1} u+\beta_{2} u^{2}+\beta_{3} u^{3}+\varepsilon$,

where $y$ is the predicted outcome of the model, $\beta_{i}$ values are constants, $u$ is the wind speed and $\varepsilon$ is the residual being normally distributed.

Adjusting $\mathrm{PO}_{\mathrm{TI}}$ with the model

$\mathrm{PO}_{\mathrm{TI}_{\text {norm }}}(u)=\frac{\mathrm{PO}_{\mathrm{TI}}}{\beta_{0}+\beta_{1} u+\beta_{2} u^{2}+\beta_{3} u^{3}}$

enables us to select constant thresholds. For the wind speed range in partial load, the polynomial is always greater than zero. At AV4 the constants of the third-order polynomial are $\beta_{0}=99.9, \beta_{1}=-32.5, \beta_{2}=3.9$ and $\beta_{3}=-0.16$ (see Sect. 4.4).

\subsection{Classification of wake magnitude}

In this section, we describe the methodology to establish thresholds for subsetting the measurements into weak, medium and strong wake effects. The thresholds are estimated with a three-step approach. First we select the normalised power (waked turbine normalised by the power of a free-flow turbine) for a small sector $\left(10^{\circ}\right)$ in the full wake for the relevant wind speed range $\left(8 \pm 1 \mathrm{~m} \mathrm{~s}^{-1}\right.$; Fig. 5a). Secondly we eliminate the dependence on wind direction by
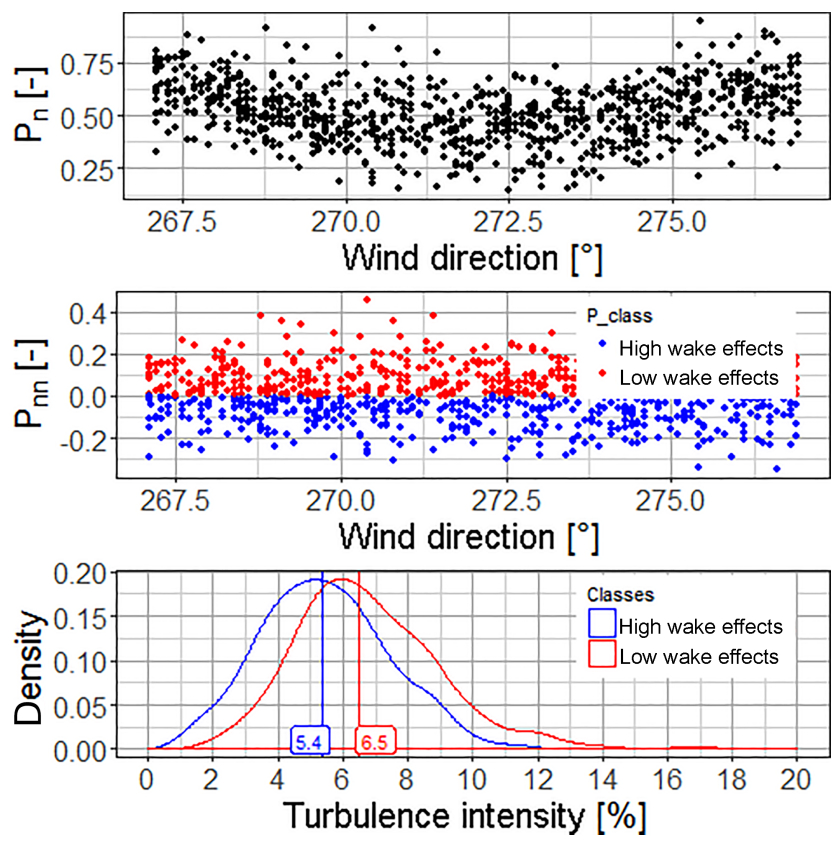

Figure 5. (a) Power of AV5 normalised with the power of AV4 for a $10^{\circ}$ sector around the full wake for wind speed range $8 \pm 1 \mathrm{~m} \mathrm{~s}^{-1}$. (b) Wind direction dependence-corrected normalised power. Each $2^{\circ}$ bin is normalised with its bin average. Data are classified into high and low wake effects. (c) Density distribution of the turbulence intensity from the met mast for each data subset with median.

subtracting from the normalised power $P_{\mathrm{n}}$ its mean value of each wind direction bin (bin width $=2^{\circ}$ ) and obtain $P_{\mathrm{nn}}$ (See Fig. $5 b)$.

The third step divides the data set into high wake effects (values $<0$ ) and low wake effects (values $>=0$ ). The median of each data subset is proposed to allocate the thresholds (See Fig. 5c).

\section{Results and discussion}

\subsection{Stability and turbulence intensity classification}

For the selected period at alpha ventus, Fig. 6 shows the stability distribution with the proposed thresholds of $\zeta=33 / L$ from Table 1 . There is a clear tendency toward more stable conditions with increasing wind speed. This trend is also visible with turbulence intensity measured at FINO1. The strong wind speed dependence of $\mathrm{PO}_{\mathrm{TI}}$ leads to an overestimation of this behaviour. The proposed normalisation as described in Eq. (6) reduces this information.

Figure 7 presents the data from FINO1 with bin-averaged met mast turbulence intensity measured at $100 \mathrm{~m}$ (TI_100), turbulence intensity from the turbine nacelle anemometer at hub height (AV4_TI), the power law coefficient from 40 and $90 \mathrm{~m}$ of height (alpha_40_90) and the standard deviation of the power divided by the average power (AV4_POTI). Each 
signal is plotted as a function of the wind speed for the three proposed stability classes based on $\zeta=\frac{33}{L}$.

For all signals in Fig. 7 the differences between the stability classes are visible. Whereas shear (See Fig. 7c) has problems in light winds, it gives the best results for higher wind speeds. Turbulence intensity (See Fig. 7a) is the most constant signal for the selected wind speed range. The turbulence intensity measured at the nacelle (See Fig. 7b) is much higher due to the location of the anemometer behind the rotor. This introduces variation and weakens the ability to distinguish between the stability classes. The relationship between the standard deviation of the power divided by the average power (See Fig. 7d) and the wind speed is very dominant and can be approximated with a third-order polynomial.

\subsection{Impact on power production}

Alpha ventus data from almost 4 years of operation are used to evaluate the influence of atmospheric stability and turbulence intensity on the wake development. Figure 8 shows the different wake behaviour under different turbulence conditions. The top row of plots shows the single-wake condition of turbine AV5 in the wake of AV4. The second row displays the same evaluation but for the double-wake condition of AV6 in the wake of AV4 and AV5. The left side is a normalised power deficit as a function of the wind direction for a wind speed range from 7 to $9 \mathrm{~m} \mathrm{~s}^{-1}$. On the right side is the normalised power as a function of the wind speed for a sector width of $10^{\circ}$. Each graph indicates the total number $N$ of data points which have been split into stable (blue dots), neutral (green diamonds) and unstable (red triangles) data sets. Each symbol is the average of a $2^{\circ}$ bin $\left(2 \mathrm{~m} \mathrm{~s}^{-1}\right.$ bin) and the error bars indicate the standard error of the mean.

For the single wake, a clearly distinguishable difference between the stable and unstable power deficit is visible. The largest deviation is found in the full wake. The second wake has a less pronounced difference in power, which can be explained by the fact that the first turbine operating in the wake supports the mixing with the ambient wind speed. Another interesting effect is noticeable in the top left plot. The difference in power for the different stabilities is higher at the right-hand side of the deficit in the downstream direction. This right drift of the wake in stable conditions has also been observed in LES simulations by Vollmer et al. (2016). This effect is even more pronounced when the data are distinguished with $\zeta=33 / L$ (See Fig. 9). The total magnitude of wake effects is better distinguished by the classification with turbulence intensity. For this reason we will consider turbulence intensity as a reference from now on.

The turbulence intensity for this classification has been measured at $100 \mathrm{~m}$, which is the largest height at the FINO1 met mast. The second height of the FINO1 met mast (90 m) is closer to hub height $(92 \mathrm{~m})$, but the strong mast structure and the boom orientation of $135^{\circ}$ cause disturbance for wind directions within the selected sector for our investigation. No further correction, e.g. to account for the difference in height, was necessary according to the findings of Tuerk (2008).

For the wind farm Nordsee Ost (NO), only 1 full year of SCADA data and 6 months of lidar data are available for this investigation. Eighteen PPI scans (as described in Sect. 2.5) with full-wake conditions are available and categorised according to the classification in Table 1. Figure 10 displays the wind speed measured with the lidar normalised with the inflow wind speed measured at the met mast. The wind speed recovers faster for the unstable turbulence class than for the neutral and stable classes. The second and third turbine in the row for the investigated wind direction are marked with blue vertical lines. The decreased wind speed in the induction zone in front of each downstream turbine is clearly visible. The error bars indicate the standard error of the mean. For the stable class $\mathrm{TI} \leq 4 \%$, only one set of PPI scans is available.

\subsection{Correlation analysis}

In the next step, we correlate the SCADA signals described in Sect. 3.2 with the turbulence intensity measured at the mast. In Fig. 11 a panel plot is displayed. The graphs on the diagonal present the histogram and density distribution for the respective variable. The panels above the diagonal provide the Pearson correlation coefficients. The lower panels are scatter plots for the two variables with a fitted linear regression line. The colours of the points indicate the three stability classifications (blue: stable, green: neutral, red: unstable) determined with the met mast turbulence intensity.

The correlation between met mast and turbine TI in the panel at row 1 , column 2 equals 0.55 . This poor result can be explained by the nacelle wind speed measurement position behind the rotor, which induces additional disturbance in the flow.

The highest correlation with the met mast TI is obtained with the standard deviation of the turbine power divided by its average active power $\left(\mathrm{PO}_{\mathrm{TI}, \mathrm{AV} 4}\right)$ in the panel at row 1 , column 5. Although a correlation of 0.66 is not perfect, it is still better than the turbulence measured with the nacelle cup anemometer. Especially in the low-turbulence region, the scatter plot proves to be denser. Very similar results are obtained when applying the same analysis to AV1 and AV2.

To check the validity of these results, we use data from Nordsee Ost (NO). Figure 12 provides the information corresponding to Fig. 11 but for a different turbine type, met mast and location in the North Sea.

The correlation reveals the best result for the $\mathrm{PO}_{\mathrm{TI}, \mathrm{NO}} 47$ signal (0.62). $\mathrm{TI}_{\mathrm{NO} 47}$ derived from the nacelle cup anemometer gives 0.60 . The difference between these two signals is much smaller than in alpha ventus. A different blade design and the distinct turbine nacelle met mast layout might be the reason for this.

Both correlation analyses show that the new artificial SCADA signal, derived from the standard deviation of the power divided by its average active power $\mathrm{PO}_{\mathrm{TI}}$, is the most 

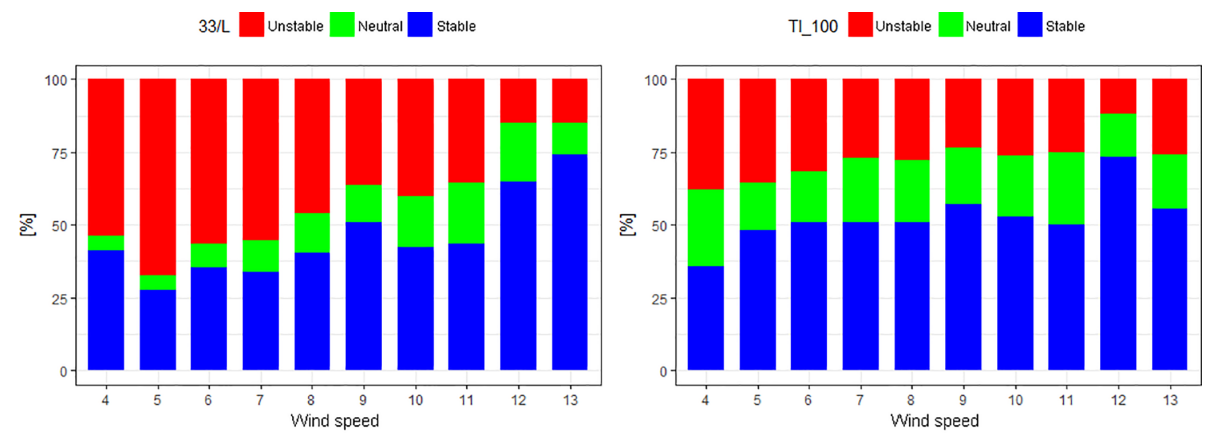

AV4_POTI_norm $\square$ Unstable $\square$ Neutral $\square$ Stable

AV4_POTI $\square$ Unstable $\square$ Neutral $\square$ Stable
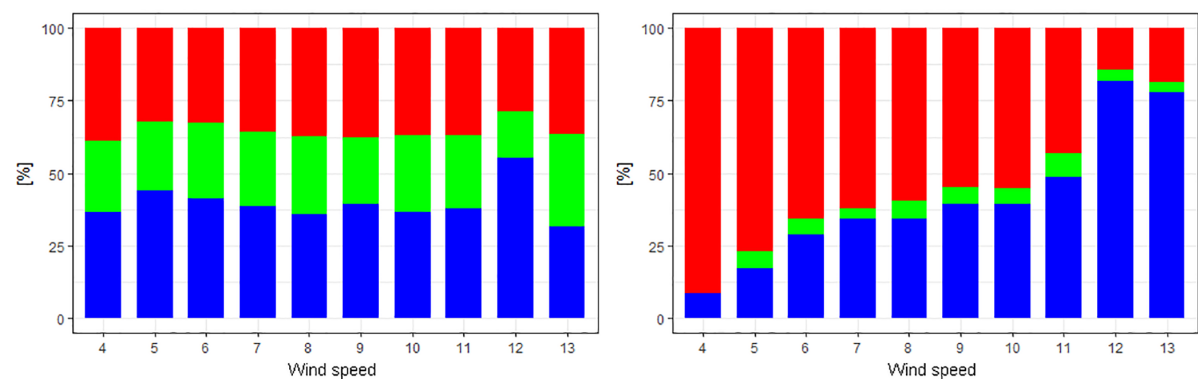

Figure 6. Distribution of stability based on $\zeta$ as a function of wind speed for different parameters of interest.
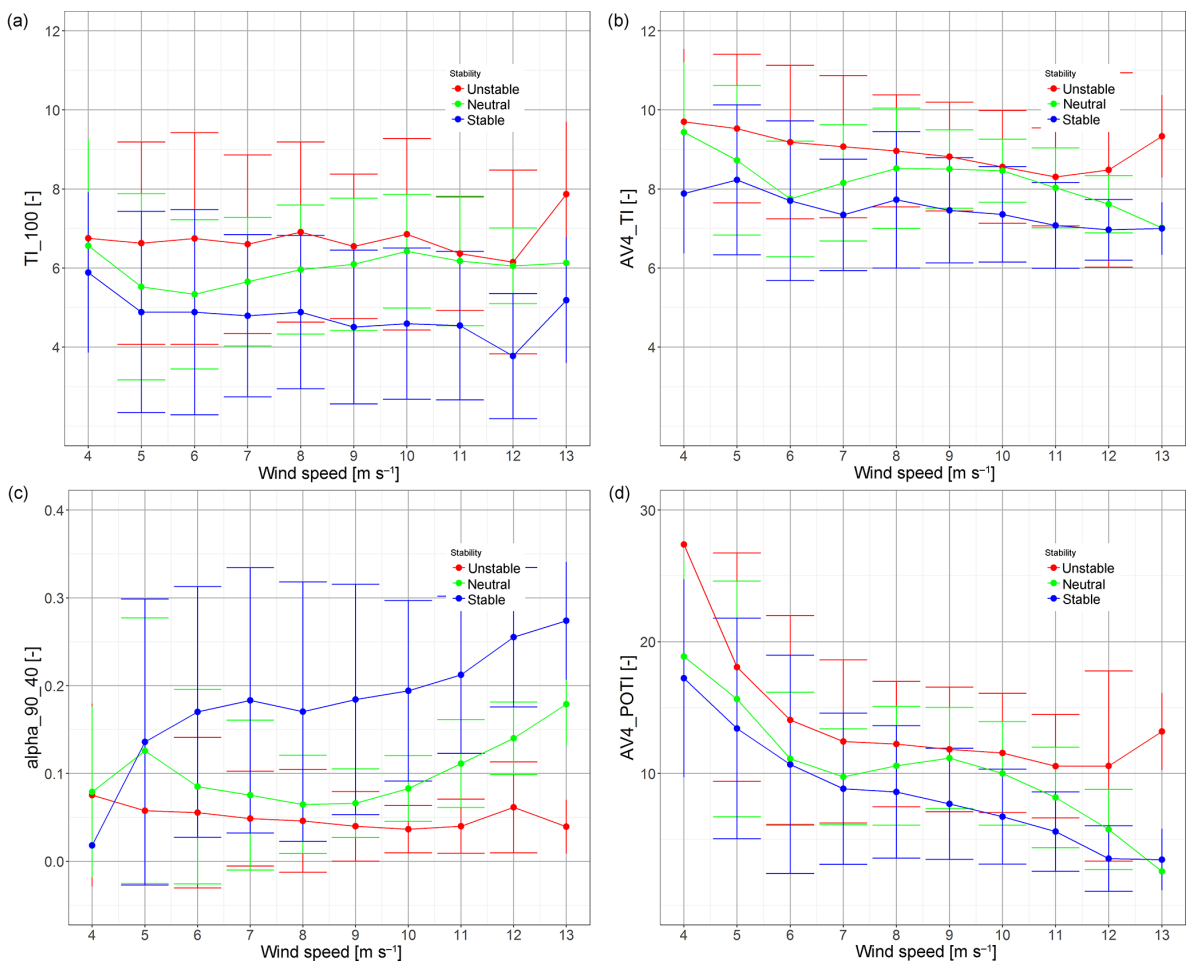

Figure 7. (a) Turbulence intensity at FINO1, (b) turbulence intensity at AV4, (c) power law coefficient for shear at FINO1 heights of 40 and $90 \mathrm{~m}$ and (d) standard deviation of the power divided by the average power for free-flow conditions at AV4. All four measurements are provided as a function of the wind speed for three stability classes based on $\zeta=\frac{33}{L}$. 

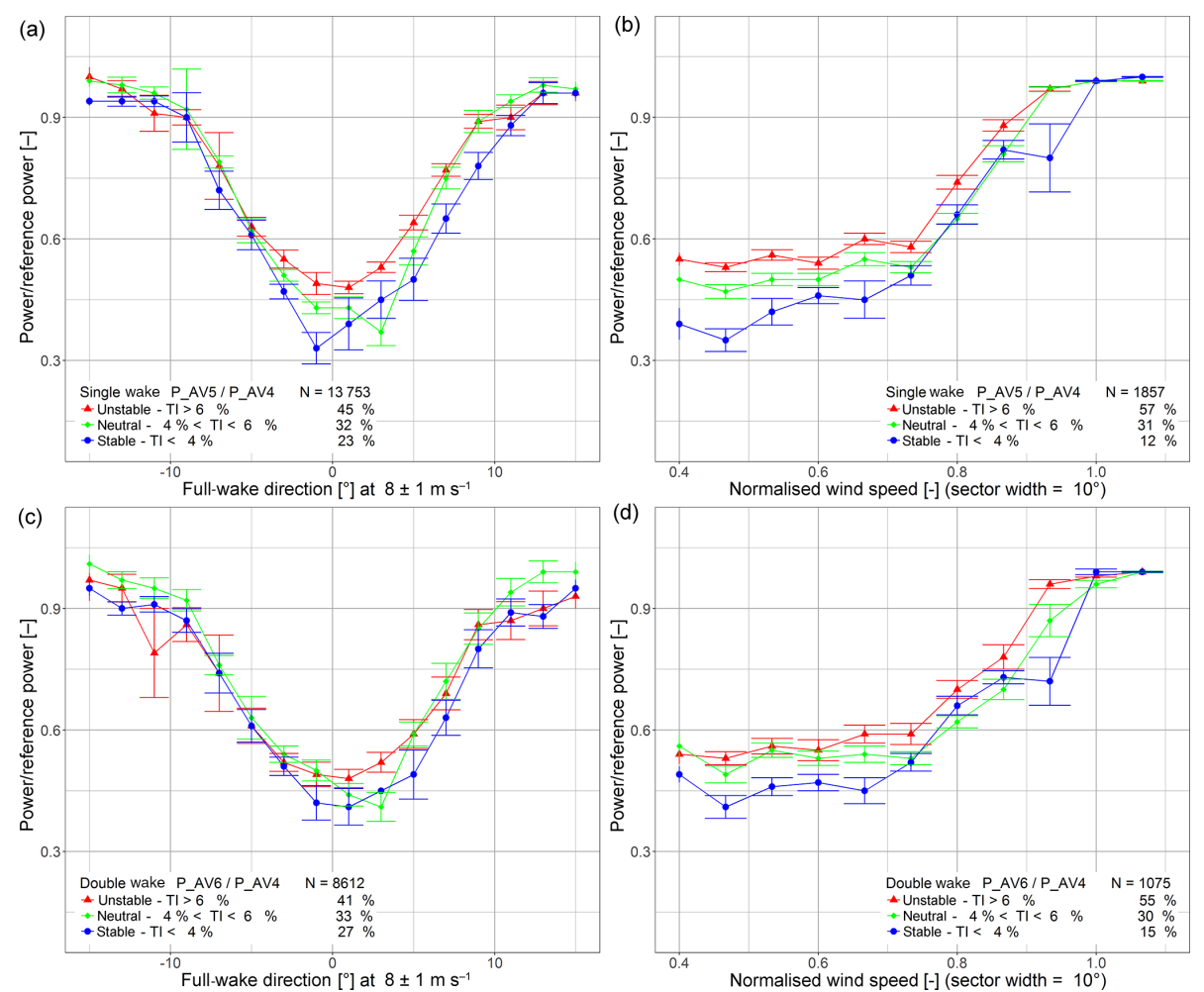

Figure 8. Wake effects in alpha ventus (AV) under different atmospheric conditions classified by met mast turbulence intensity. Power of downstream turbine normalised with free-flow turbine. Upper row: single wake, bottom row: double wake. Left column: normalised power as a function of wind direction, right column: normalised power as a function of wind speed.

suitable among the selected signals to substitute a met mast $\mathrm{TI}_{\text {mast }}$ for our purpose. In the next section, we check the influence of this new signal on the estimated power production in the wake.

\subsection{New classification and validation}

In Sect. 4.2 we demonstrated the correlation of the SCADA signal $\mathrm{PO}_{\mathrm{TI}}$ with the turbulence intensity measured at a met mast in free-flow conditions. In Fig. 7d a strong wind speed dependence for the range of interest prevents a constant threshold establishment. Therefore the adjustment with Eq. (6) is proposed. Figure 13 shows $\mathrm{PO}_{\mathrm{TI}_{\text {norm }}}$ as a function of wind speed for the three stability classes based on $\zeta$. The error bars are 1 standard deviation.

For AV4 the constants of the third-order polynomial are $\beta_{0}=99.9, \beta_{1}=-32.5, \beta_{2}=3.9$ and $\beta_{3}=-0.16$.

With the methodology from Sect. 3.3 we obtain different density distributions for high and low wake effects (See Fig. 14). The thresholds are derived from the median of the data distribution. For $\zeta$ we obtain exactly the same values as proposed in Table 1.

Comparing the two turbulence intensities in Fig. 14a and c, one can clearly see the increased turbulence behind the rotor, especially for low TI values. The distribution for the na- celle measurement is compressed in a way that the low measurements have up to $4 \%$ difference but the high turbulence intensities are more or less comparable. This effect reduces the ability of the nacelle turbulence intensity to distinguish between the wake magnitudes. A more clear separation between the wake classes can be achieved with the newly proposed $\mathrm{PO}_{\mathrm{TI}_{\text {norm }}}$.

The quality of the established relationship in terms of dependence on turbine type, layout and location of the wind farm is tested by applying the same classification on a different wind farm where no met mast is available.

In the next sections, the ability of this new signal to distinguish between different environmental stratifications is analysed. Table 2 shows the proposed thresholds for the different parameters under investigation.

\subsubsection{Alpha ventus (AV)}

The classification of wake effects by the $\mathrm{PO}_{\mathrm{TI}_{\text {norm }}}$ signal is illustrated in Fig. 15, analogous to Fig. 8 in which the turbulence intensity $\mathrm{TI}_{\text {mast }}$ is used.

A clear difference in power production between stable and unstable cases can be identified in the single wake. The differences in double wake are again less pronounced. Compared to the TI classification, the curves for the neutral case 

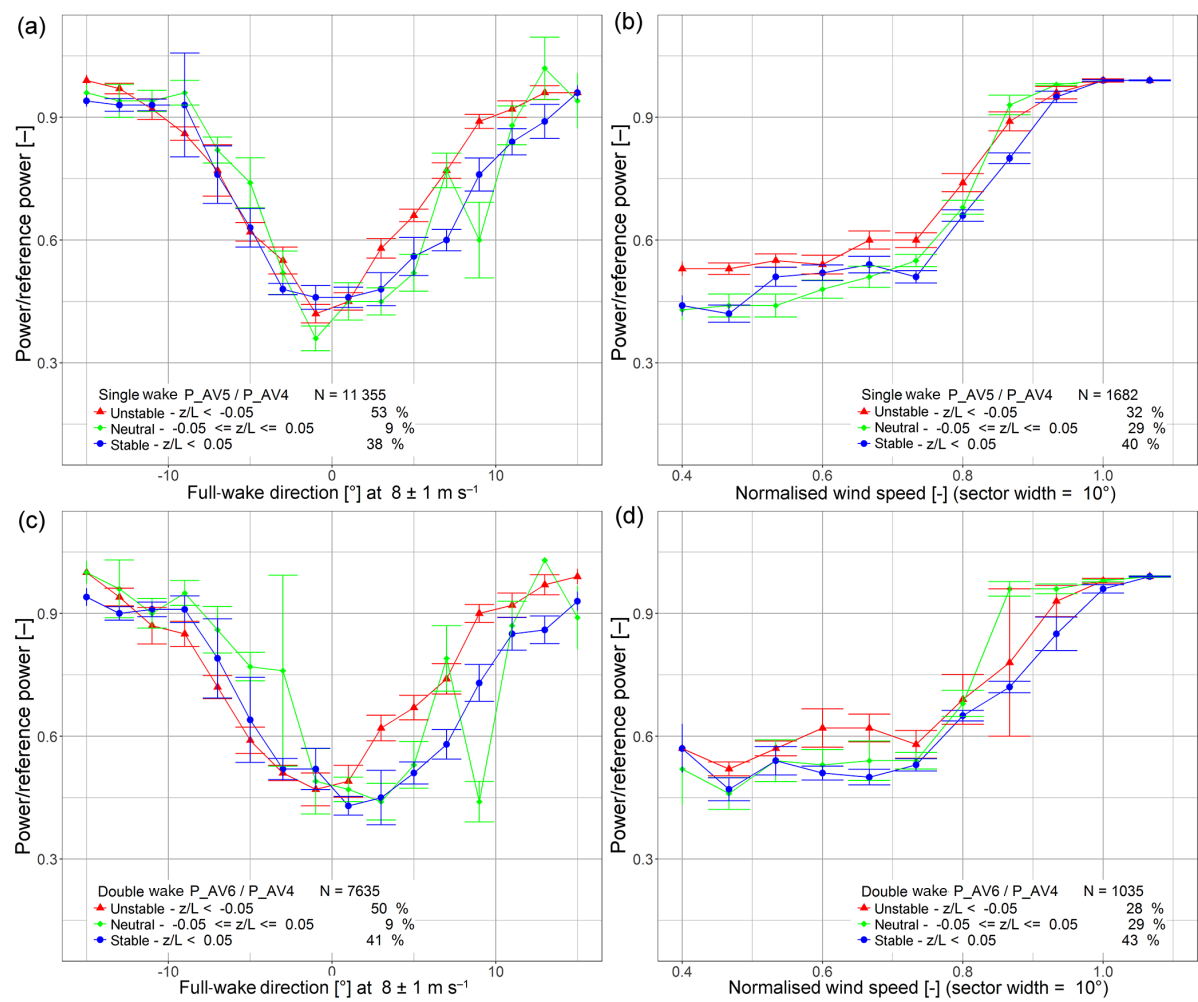

Figure 9. Wake effects in alpha ventus (AV) under different atmospheric conditions classified by $\zeta=33 / L$. Power of downstream turbine normalised with free-flow turbine. Upper row: single wake, bottom row: double wake. Left column: Normalised Power as a function of wind direction, right column: Normalised power as a function of wind speed.

Table 2. Summary of thresholds for the different classes of interest at alpha ventus.

\begin{tabular}{lllll}
\hline Category & $\zeta=z / L[-]$ & $\mathrm{TI}_{100}[\%]$ & $\mathrm{AV} 4 \mathrm{TI}[\%]$ & AV4_POTI $_{\text {norm }}[-]$ \\
\hline Weak wakes & $\zeta<-0.05$ & $\mathrm{TI}_{100}>6.5$ & $\mathrm{AV4}$ TI $>8.3$ & POTI $_{\text {norm }}<0.8$ \\
Medium wakes & $-0.05 \leq \zeta \leq 0.05$ & $5.4 \leq T_{100} \leq 6.5$ & $7.6 \leq \mathrm{AV} 4 \mathrm{TI} \leq 6.5$ & $0.8 \leq$ POTI $_{\text {norm }} \leq 1.1$ \\
Strong wakes & $\zeta>0.05$ & $T_{100}<5.4$ & $\mathrm{AV4} 4 \mathrm{TI}<7.6$ & POTI $_{\text {norm }}>1.1$ \\
\hline
\end{tabular}

are not as clear as between the stable and unstable curves, and in the normalised power curve plots (right column) the stable conditions can only be highlighted up to the wind speed of rated power for the free-flow turbine. This can be explained by the fact that at rated power the pitch controller rather than the power variation governs the turbine reaction to turbulence intensity. This leads in Eq. (4) to a significant decrease in the numerator and keeps the denominator constant.

\subsubsection{Nordsee Ost (NO)}

The classification of wake effects in Fig. 16 is based on $\mathrm{PO}_{\mathrm{TI}}$ norm and analogous to Fig. 10 in which turbulence intensity $\mathrm{TI}_{\text {mast }}$ is used. For these plots the Gaussian-fitted minima of the normalised wind speed (wake centres) measured by the lidar are plotted for each distance behind NO48.

This result states the ability of $\mathrm{PO}_{\mathrm{TI}_{\text {norm }}}$ to distinguish between different wake effects. The single wake has a less pro- nounced difference between the three classes, and the slope of the wind speed recovery is smaller than the double-wake case; $5 \mathrm{D}$ behind the first turbine, the wind speed has recovered to approximately $70 \%$ of the free-flow wind speed, and in the second wake $5 \mathrm{D}$ behind $\mathrm{NO} 44$, we see more than $75 \%$. This fact leads to the performance increase at the third turbine (NO45) compared to the second turbine (NO44). The wake-added turbulence of NO48 helps to recover the wind speed.

\subsubsection{Ormonde (OR)}

Finally, the transferability of classification boundaries to other wind farms where no met mast is available is of interest.

First we have a look at the sensitivity of the signal $\mathrm{PO}_{\mathrm{TI}}$ in terms of turbulence from neighbouring turbines and wind farms. In Fig. 17, the directional bin-averaged $\mathrm{PO}_{\mathrm{TI}}$ from 


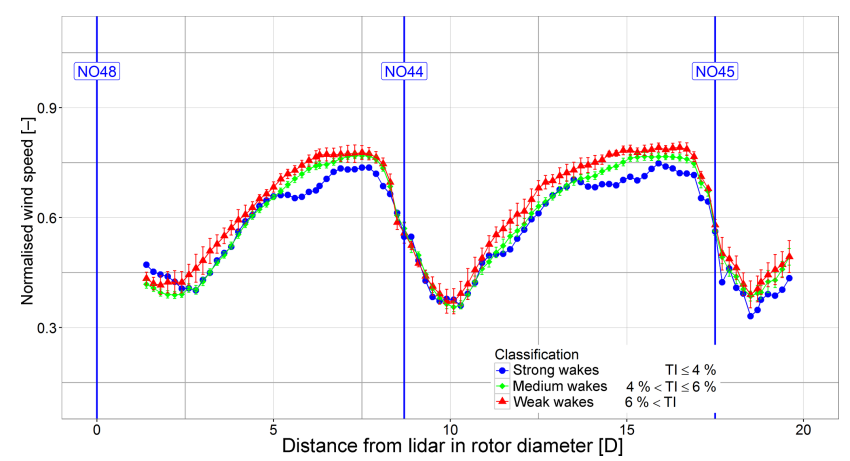

Figure 10. Wind speed recovery at wake centre at hub height behind NO48 for different turbulence stability classes. The wind speed is normalised with the inflow wind speed and the distance from the lidar on NO48 downstream is displayed in multiples of rotor diameters.

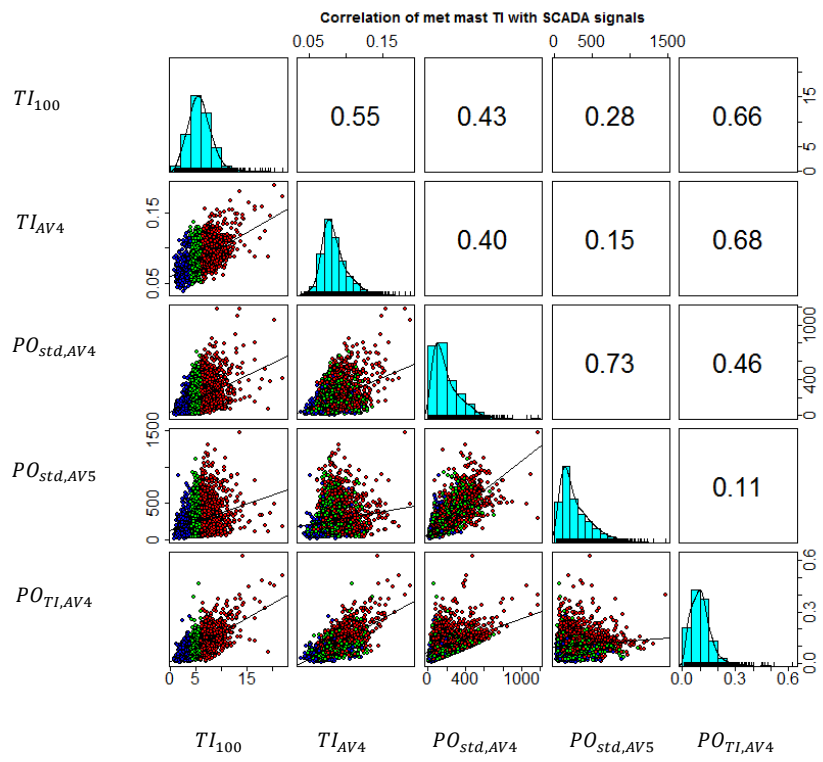

Figure 11. Correlation matrix. Turbulence intensity from met mast $\left(\mathrm{TI}_{100}\right)$ is correlated with the TI measured with the nacelle anemometer of $\mathrm{AV} 4\left(\mathrm{TI}_{\mathrm{AV} 4}\right)$, the standard deviation of the $10 \mathrm{~min}$ power of AV4 ( $\left.\mathrm{PO}_{\text {std, AV4 }}\right)$, the standard deviation of the $10 \mathrm{~min}$ power of AV5 $\left(\mathrm{PO}_{\mathrm{std}} \mathrm{AV} 5\right)$ and the standard deviation of the power divided by the average power of AV4 ( $\left.\mathrm{PO}_{\mathrm{TI}}, \mathrm{AV} 4\right)$. All dimensions are in \% except for the standard deviation of the power, which is in $\mathrm{kW}$.

OR24 is able to identify the location of its neighbours. The magnitude allows us to determine which turbine is next (OR25 at 4.2 D) and which is further away (OR22 at 6.7 D, OR23 at 6.6 D and OR21 at 9.1 D).

The grey area represents the geometrical location of the neighbouring wind farms Walney 1 and 2. The closest distance to OR24 is Walney 1 at approximately $38.8 \mathrm{D}$ (SWT3.6-107 Siemens). The two peaks at 208 and $255^{\circ}$ are wind directions for which multiple turbines of the neighbouring

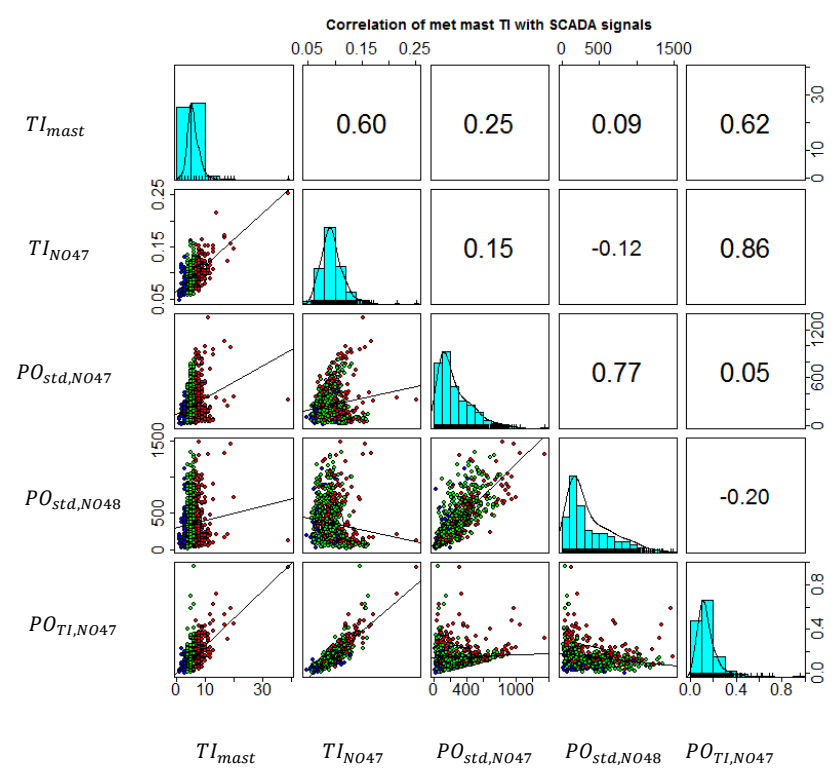

Figure 12. Correlation analysis for Nordsee Ost. Turbulence intensity $\left(\mathrm{TI}_{\text {mast }}\right)$ measured at hub height is correlated with the TI measured with the nacelle anemometer of $\mathrm{NO} 47\left(\mathrm{TI}_{\mathrm{NO}} 47\right)$, the rotorestimated wind speed $\left(\mathrm{TI}_{\mathrm{NO} 47_{\mathrm{ues}}}\right)$, the standard deviation of the 10 min power of $\mathrm{NO} 47\left(\mathrm{PO}_{\text {std, } \mathrm{NO}} 47\right)$, the standard deviation of the 10 min power of $\mathrm{NO} 48\left(\mathrm{PO}_{\text {std,NO48 }}\right)$ and the standard deviation of the power divided by the average power of NO47 ( $\left.\mathrm{PO}_{\mathrm{TI}, \mathrm{NO}} 47\right)$. All dimensions are in $\%$ except for the standard deviation of the power, which is in $\mathrm{kW}$.

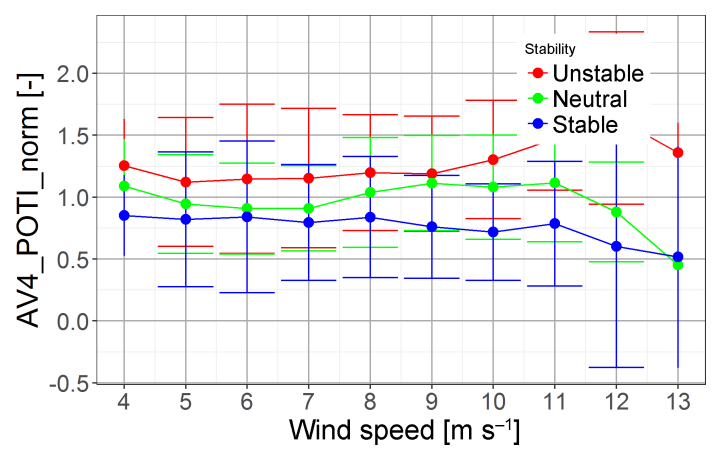

Figure 13. Normalised SCADA signal $\left(\mathrm{PO}_{\mathrm{TI}_{\mathrm{norm}}}\right)$ for the classification of the magnitude of wake effects.

wind farm are aligned in a clear row of full-wake situations. The increase from 345 to $15^{\circ}$ can be explained by the coastline coming quickly closer in the clockwise direction.

Secondly we have a look at the influence on the wake recovery. With the south-westerly wind direction, we focus on single-wake, double-wake and triple-wake conditions behind turbine OR27 for a sector of $10^{\circ}$ around the full-wake situation. For the north-westerly wind directions we investigate the rows of turbines behind OR23. The main differences between these two directions are the average level of inflow turbulence intensity and the different spacing between 

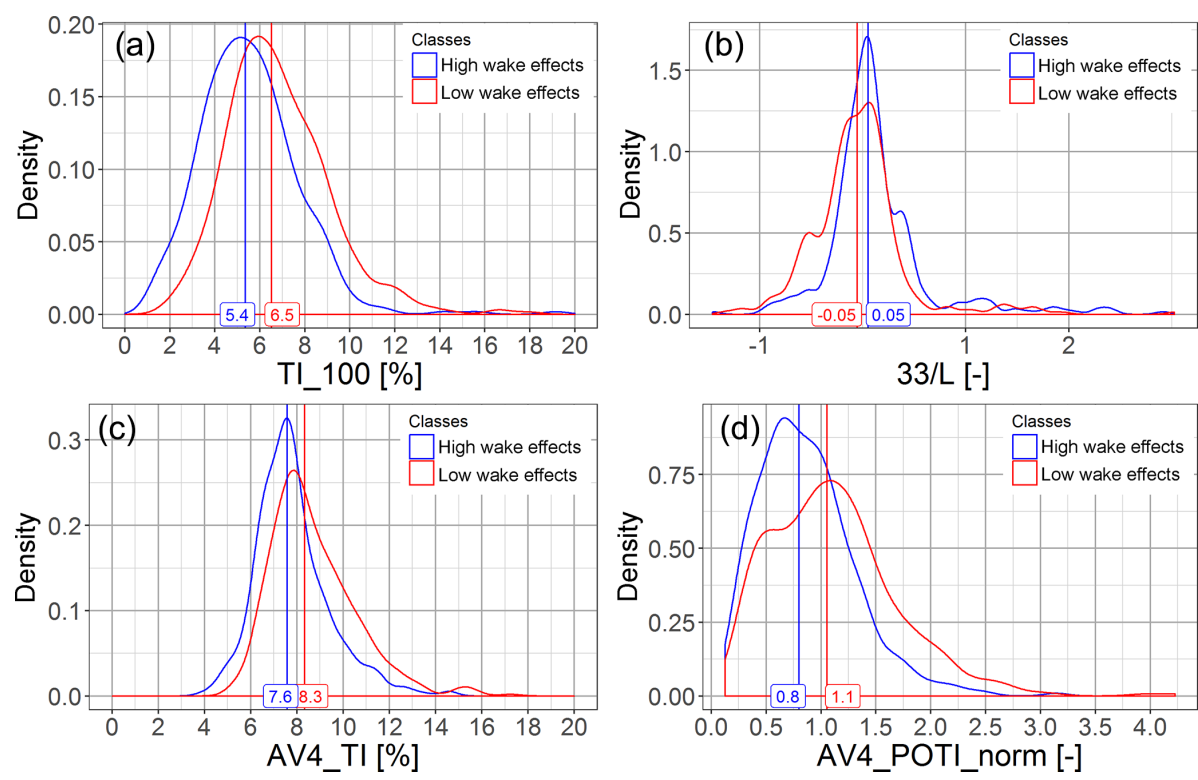

Figure 14. The thresholds displayed as vertical lines representing the median of the density distribution for the signal of interest.
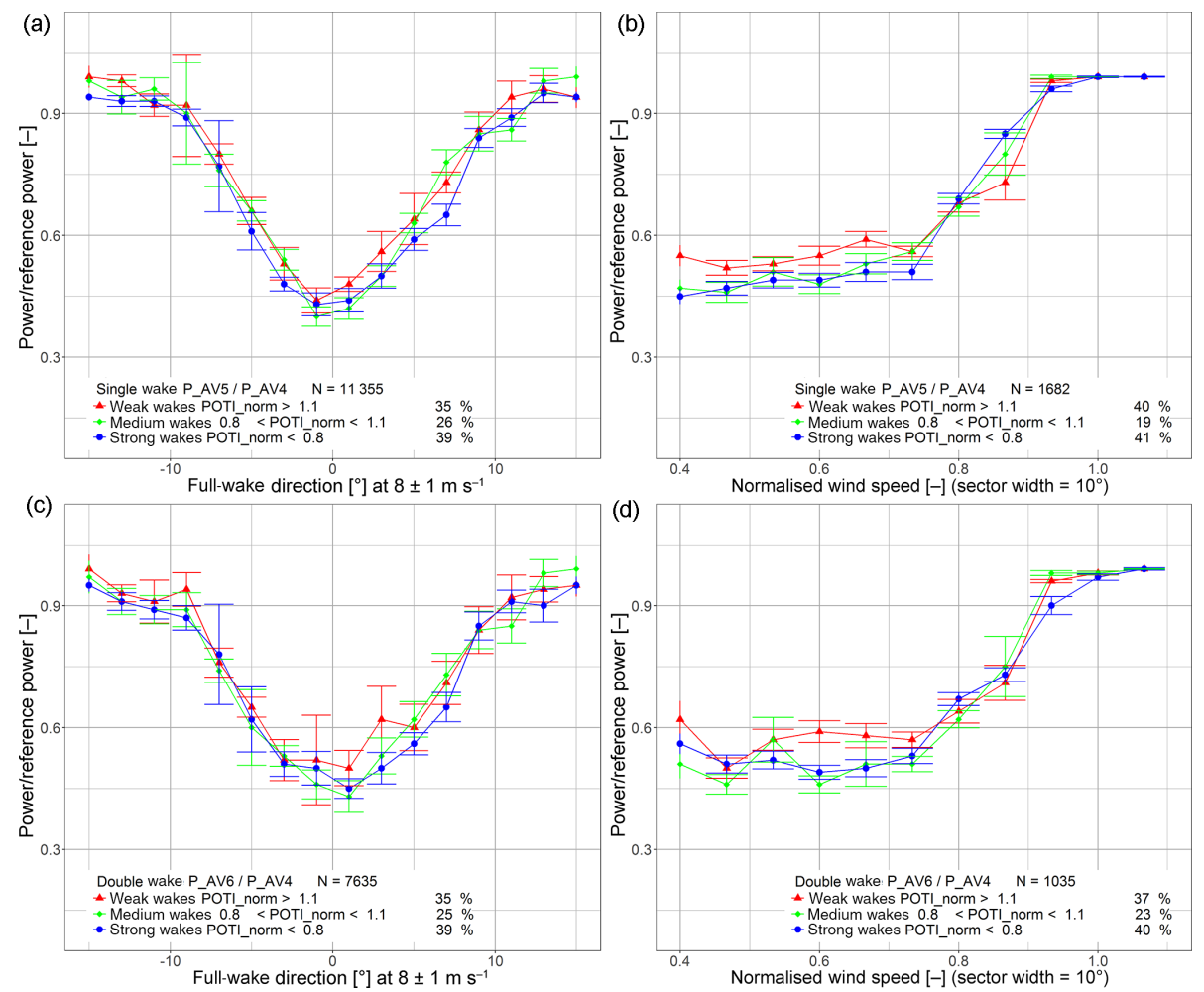

Figure 15. Stability classification with the $\mathrm{PO}_{\mathrm{TI}}$ norm value. Power of waked turbine normalised with free-flow turbine. Upper row: single wake, bottom row: double wake. Left column: normalised power as a function of wind direction, right column: normalised power as a function of wind speed.

the turbines. In Fig. 17, the inflow turbulence level from the north-west (sector of 302 to $322^{\circ}$ ) is much lower (bin average $\overline{\mathrm{PO}} \approx 12.5 \%$ ) than from the south-west (sector of 192 to $222^{\circ}$, bin average $\overline{\mathrm{PO}_{\mathrm{TI}}} \approx 17.5 \%$ ) due to the wake effects from Walney 1 at more than $38 \mathrm{D}$ of distance.

For the north-westerly wind direction, Fig. 18 provides a view on different wake effects for the proposed classifica- 


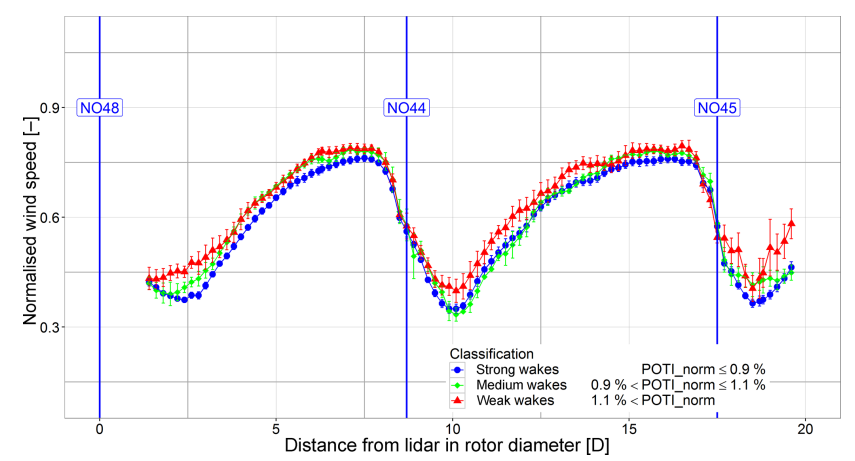

Figure 16. Wind speed recovery behind NO48 for different $\mathrm{PO}_{\mathrm{TI}_{\text {norm }}}$ classes. The wind speed is normalised with the inflow wind speed and the distance from the lidar on NO48 downstream is displayed in multiples of rotor diameters.

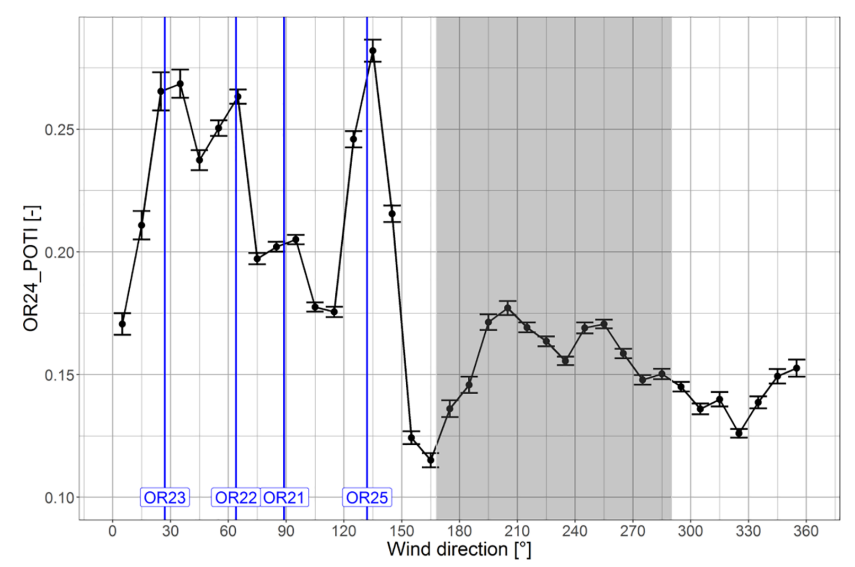

Figure 17. The signal $\mathrm{PO}_{\mathrm{TI}}$ is sensitive to wake-induced turbulence from neighbouring turbines and wind farms. With $\mathrm{PO}_{\mathrm{TI}}$ from turbine OR24 it is even possible to rank the distance of the neighbours, with OR25 being the closest at 4.2 D and OR21 the farthest at 9.1 D.

tion. The normalised power for each turbine in the row behind OR23 is displayed (wind from left to right). Wind speed is filtered for $8 \pm 1 \mathrm{~m} \mathrm{~s}^{-1}$ and the wind direction is $316^{\circ}$ with a sector width of $10^{\circ}$. The largest wake effects are detected at OR22. This underlines the observation from the lidar measurements in NO. The first wake is the strongest and all consecutive wakes are better mixed due to wake-added turbulence. The difference in power production between high- and low-turbulence conditions is in the range of $10 \%$, which also demonstrates the importance of this effect for wake model developers to take into account.

The south-westerly wind direction is analysed in Fig. 19, which is a similar illustration as in Figs. 8 and 9. It is still possible to identify different wake behaviour for the different classes, but the effect is less pronounced than in the previous examples. A higher level of inflow turbulence intensity contributes to the mixing of the wake with free wind. Hence at

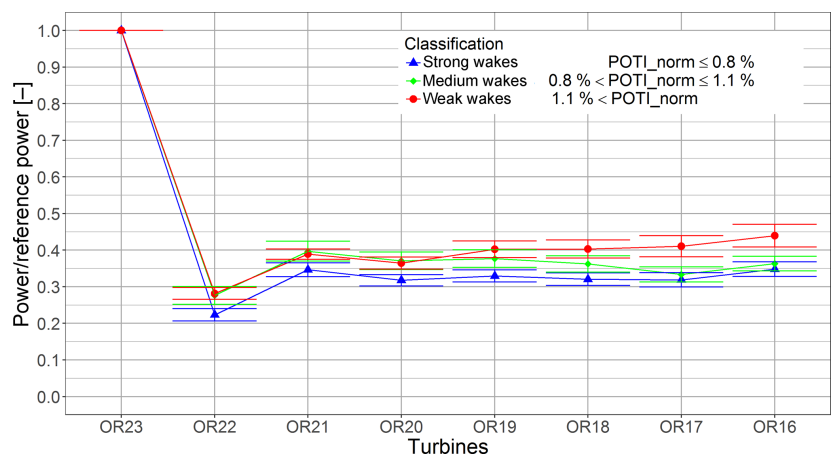

Figure 18. Normalised power for each turbine along the row behind OR23 for a wind direction of $312^{\circ}$, a $10^{\circ}$ sector width and $8 \mathrm{~m} \mathrm{~s}^{-1} \pm 1$. Stability classes distinguished with the signal $\mathrm{PO}_{\mathrm{TI}_{\text {norm }}}$ from OR23.

lower inflow turbulence levels the effect of the wake-added turbulence is larger.

Further investigations are necessary to account for controller properties and to fill the normalised wind speed range $(0.75-1)$ beyond the rated wind speed of the turbine in freeflow conditions.

In performance monitoring of offshore wind farms, the newly aggregated SCADA signals can be used as an auxiliary quantity to classify different atmospheric conditions. Advanced engineering wake models, which are able to take turbulence intensity or stability parameters into account, may be parameterised by these artificial turbine signals in order to improve their prediction of wind turbine power production under waked conditions.

\section{Conclusions}

Measured data from three different offshore wind farms, two met masts, one buoy and one long-range lidar have been analysed to identify different influences on power production for turbines operating in the wake. We have validated the method described in Dörenkämper (2015), which proposes using the turbulence intensity to describe the power production in the wake, and compared it with the atmospheric stability evaluation proposed by Ott and Nielsen (2014). In this case, turbulence intensity could better distinguish between the magnitudes of wake effects. A correlation analysis was performed, and for wind speeds in partial load operation, the standard deviation of the power divided by its average power $\left(\mathrm{PO}_{\mathrm{TI}}\right)$ was identified as having similar behaviour to that of the turbulence intensity. A sensitivity check for $\mathrm{PO}_{\mathrm{TI}}$ revealed very detailed responsiveness to increases in turbulence due to neighbouring turbines and wind farms. Effects from wind farm neighbours are detectable even more than 38 rotor diameters away. A strong wind speed dependence of this signal can be eliminated by normalisation with a thirdorder polynomial fitted to the data. A classification of dif- 

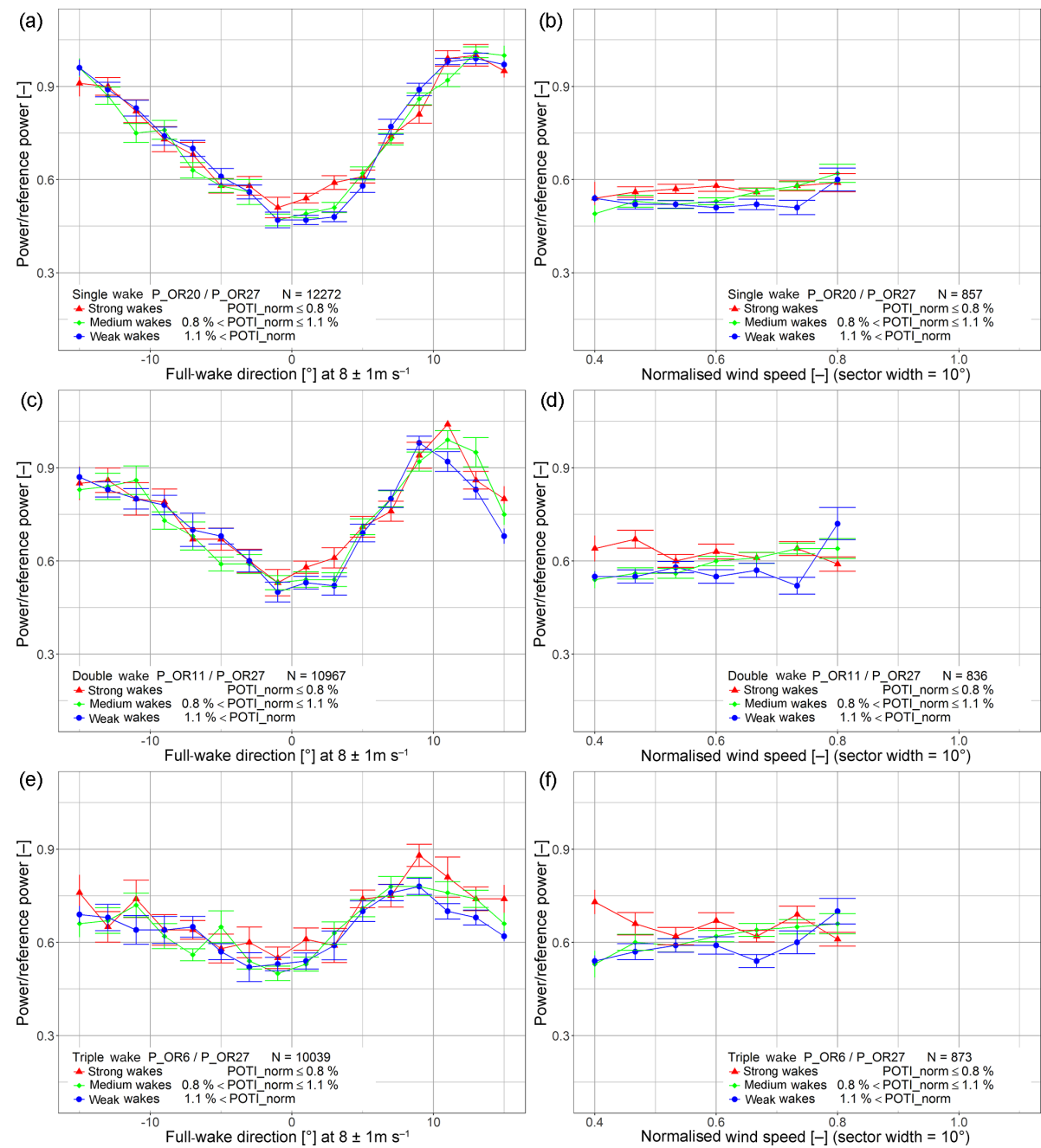

Figure 19. Wake effects in Ormonde (OR) under different conditions. Power of downstream turbine normalised with free-flow turbine. First row: single wake, second row: double wake and third row: triple wake. Left column: normalised power as a function of wind direction, right column: normalised power as a function of wind speed.

ferent turbine behaviour based on this adjusted $\mathrm{PO}_{\mathrm{TI}_{\mathrm{norm}}}$ was analysed and compared to the classification with turbulence intensity TI.

Both signals can distinguish between stronger and weaker wake effects. The magnitude of influence of the $\mathrm{PO}_{\mathrm{TI}_{\text {norm }}}$ signals on wake effects is dependent on the level of inflow turbulence intensity. Higher inflow turbulence has higher wake mixing, and therefore the wake-added turbulence has a less pronounced contribution.

Using $\mathrm{PO}_{\mathrm{TI}_{\text {norm }}}$ to predict wakes more accurately is a promising approach, but further investigations are necessary to take controller properties into account in order to fill the wind speed range beyond the rated wind speed of the turbine in free-flow conditions.

Data availability. Data are not available to the public.
Competing interests. The authors declare that they have no conflict of interest.

Special issue statement. This article is part of the special issue "The Science of Making Torque from Wind (TORQUE) 2016". It is a result of the The Science of Making Torque from Wind (TORQUE 2016), Munich, Germany, 5-7 October 2016.

Acknowledgements. The presented work is partly funded by the Commission of the European Communities Research DirectorateGeneral within the scope of the project "ClusterDesign" (project no. 283145; FP7 Energy). We would like to thank Deutsche Offshore-Testfeld und Infrastruktur GmbH \& Co. KG (DOTI), Research at alpha ventus (RAVE), Forschungsplattformen in Nord und Ostsee (FINO1), Innogy SE, Vattenfall Wind Power and Senvion $\mathrm{SE}$ for making this investigation possible. Furthermore, special 
thanks go to the $\mathrm{R}$ Core Team for developing the open-source language R (R Core Team, 2015).

Edited by: Christian Masson

Reviewed by: two anonymous referees

\section{References}

Archer, C. L., Colle, B. A., Veron, D. L., Veron, F. and Sienkiewicz, M. J.: On the predominance of unstable atmospheric conditions in the marine boundary layer offshore of the U.S. northeastern coast, J. Geophys. Res.-Atmos., 121, 8869-8885, https://doi.org/10.1002/2016JD024896, 2016.

Beck, H., Trabucchi, D., Bitter, M., and Kühn, M.: The Ainslie Wake Model An Update for Multi Megawatt Turbines based on State-of-the-Art Wake Scanning Techniques, in Proceedings of the European Wind Energy Association, Barcelona, Spain, 1013 March, 2014.

Dörenkämper, M.: An investigation of the atmospheric influence on spatial and temporal power fluctuations in offshore wind farms, PhD Thesis, University of Oldenburg, Oldenburg, 2015.

Dörenkämper, M., Tambke, J., Steinfeld, G., Heinemann, D., and Kühn, M.: Influence of marine boundary layer characteristics on power curves of multi megawatt offshore wind turbines, Proceedings of 11th German Wind Energy Conference, Bremen, Germany, 7-8 November, 2012.

Dörenkämper, M., Tambke, J., Steinfeld, G., Heinemann, D., and Kühn, M.: Atmospheric Impacts on Power Curves of MultiMegawatt Offshore Wind Turbines, J. Phys. Conf. Ser., 555, 12029, https://doi.org/10.1088/1742-6596/555/1/012029, 2014.

Göçmen, T. and Giebel, G.: Estimation of turbulence intensity using rotor effective wind speed in Lillgrund and Horns Rev-I offshore wind farms, Renew. Energy, 99, 524-532, https://doi.org/10.1016/j.renene.2016.07.038, 2016.

Hamilton, N.: Functions Relating to the Smoothing of Numerical Data, CRAN R, 1-5, 2015.

Hansen, K. S., Barthelmie, R. J., Jensen, L. E., and Sommer, A.: The impact of turbulence intensity and atmospheric stability on power deficits due to wind turbine wakes at Horns Rev wind farm, Wind Energy, 15, 183-196, https://doi.org/10.1002/we.512, 2012.

Iungo, G. V. and Porté-Agel, F.: Volumetric scans of wind turbine wakes performed with three simultaneous wind LiDARs under different atmospheric stability regimes, J. Phys. Conf. Ser., 524, 12164, https://doi.org/10.1088/1742-6596/524/1/012164, 2014.

Keane, A., Aguirre, P. E. O., Ferchland, H., Clive, P., and Gallacher, D.: An analytical model for a full wind turbine wake, J. Phys. Conf. Ser., 753, 32039, https://doi.org/10.1088/17426596/753/3/032039, 2016.

Mittelmeier, N., Blodau, T., and Kühn, M.: Monitoring offshore wind farm power performance with SCADA data and an advanced wake model, Wind Energ. Sci., 2, 175-187, https://doi.org/10.5194/wes-2-175-2017, 2017.

Monin, A. S. and Obukhov, A. M.: Basic laws of turbulent mixing in the surface layer of the atmosphere, Inst. Contract Number, 24(19604), 163-187, available at: http://mcnaughty. com/keith/papers/Monin_and_Obukhov_1954.pdf (last access: 21 May 2017), 1954.
More, G. and Gallacher, D.: Lidar Measurements and Visualisation of Turbulence and Wake Decay Length, Proceedings of the European Wind Energy Association, Barcelona, Spain, 10-13 March, 2014.

Mortensen, N. G., Nielsen, M., and Ejsing Jørgensen, H.: Offshore CREYAP Part 2 - final results, European Wind Energy Association (EWEA), Helsinki, Finland, 2 Juni 2015, 2015.

Ott, S. and Nielsen, M.: Developments of the offshore wind turbine wake model Fuga, E-0046 Report 2014, DTU Wind Energy, Lyngby, Denmark, 2014.

Özdemir, H., Versteeg, M. C., and Brand, A. J.: Improvements in ECN Wake Model, in Proceedings of the ICOWES2013 Conference, Lyngby, Denmark, 17-19 June, 2013.

R_Core_Team: R: A Language and Environment for Statistical Computing, available at: https://www.r-project.org/, R 3.3.1 ( last access: June, 2016), 2015.

Rajewski, D. A., Takle, E. S., Lundquist, J. K., Oncley, S., Prueger, J. H., Horst, T. W., Rhodes, M. E., Pfeiffer, R., Hatfield, J. L., Spoth, K. K., Doorenbos, R. K., Rajewski, D. A., Takle, E. S., Lundquist, J. K., Oncley, S., Prueger, J. H., Horst, T. W., Rhodes, M. E., Pfeiffer, R., Hatfield, J. L., Spoth, K. K., and Doorenbos, R. K.: Crop Wind Energy Experiment (CWEX): Observations of Surface-Layer, Boundary Layer, and Mesoscale Interactions with a Wind Farm, B. Am. Meteorol. Soc., 94, 655-672, https://doi.org/10.1175/BAMS-D-11-00240.1, 2013.

Sanz Rodrigo, J., Cantero, E., García, B., Borbón, F., Irigoyen, U., Lozano, S., Fernande, P. M., Chávez, R. a, Rodrigo, J. S., Cantero, E., García, B., Borbón, F., Irigoyen, U., Lozano, S., Fernande, P. M., and Chávez, R. a: Atmospheric stability assessment for the characterization of offshore wind conditions, J. Phys. Conf. Ser., 625, 12044, https://doi.org/10.1088/17426596/625/1/012044, 2015.

Schneemann, J., Trabucchi, D., Trujillo, J. J., and Voß, S.: Long range scanning lidar measurement campaign report, ClusterDesign Deliverable 7.1, ClusterDesign, Project No. 283145 (FP7 Energy), 2016.

Tambke, J., Claveri, L., Bye, J. A. T., Poppinga, C., Lange, B., von Bremen, L., and Wolff, J.-O.: Marine Meteorology for Multi-Mega-Watt Turbines, Proceedings of Copenhagen Offshore Wind, Copenhagen, Denmark, 2005.

Tuerk, M.: Ermittlung designrelevanter Belastungsparameter für Offshore-Windkraftanlagen, $\mathrm{PhD}$ Thesis, Universität zu Köln, 2008.

Türk, M. and Emeis, S.: The dependence of offshore turbulence intensity on wind speed, J. Wind Eng. Ind. Aerodyn., 98, 466-471, https://doi.org/10.1016/j.jweia.2010.02.005, 2010.

Vollmer, L., Steinfeld, G., Heinemann, D., and Kühn, M.: Estimating the wake deflection downstream of a wind turbine in different atmospheric stabilities: an LES study, Wind Energ. Sci., 1, 129141, https://doi.org/10.5194/wes-1-129-2016, 2016.

Westerhellweg, A., Cañadillas, B., Kinder, F., and Neumann, T.: Wake Measurements at alpha ventus - Dependence on Stability and Turbulence Intensity, J. Phys. Conf. Ser., 555, 12106, https://doi.org/10.1088/1742-6596/555/1/012106, 2014. 